\title{
Research on the Urbanization Quality of Xiangyang City LI Jie $^{1}$, ZHU Yan-Yang ${ }^{2}$ and SUN Xiao-Zhou ${ }^{3}$ \\ ${ }^{1,2,3}$ School of Management, Hubei University of Arts and Science, Xiangyang, Hubei, China lijielara@163.com, youngsunzyy@126.com, 454818653@qq.com
}

\begin{abstract}
As a sub-central city in Hubei province, currently the urbanization of Xiangyang is in the accelerated development stage, and the improvement of urbanization development quality (UDQ) is critical in this process. Using the analytic hierarchy process, this work constructed an evaluation system of comprehensive urbanization development measure, proposing 18 detailed indexes and discrimination standards to measure the comprehensive urbanization appraisal index of Xiangyang since 2000. After building indexes in economic structure, environmental development, social development, quality of life and population quality, we analyzed urbanization quality of each subsystem, proposing the countermeasures of promoting Xiangyang city's UDQ.

Keywords-urbanization development quality; index system; Xiangyang
\end{abstract}

\section{INTRODUCTION}

With the rapid development of economy and increasingly strong urbanization in China, the urbanization level has become one of the important indices for measuring regional development degree at present, reflecting the regional economic development level to great extent. Therefore, the study on urbanization level has significance in regional development. In multiple areas, acceleration of urbanization development is treated as the important measure and strategy for local economic development. However, a lot of urban problems, including traffic jam, air pollution and water damage, occur with rapid increase of urbanization level. Therefore, the improvement of urbanization development with rapid development becomes the focus of government and scholars.

Previous research results show that experts and scholars pay great attention to the quality research of Chinese urbanization development. However, the evaluation for cities in Hubei Province is quite few at present, with no study on evaluation for urbanization development of Xiangyang City. As the sub-central city in Hubei province and the most important city in Hanjiang ecology economic belt, Xiangyang plays a role in healthy and sustainable development of Hanjiang economic belt, and even in the whole Hubei Province with its development quality.

\section{EVALUATION FOR URBANIZATION QUALITY OF XIANGYANG CITY}

Evaluation model for study on urbanization development quality mainly adopts factor analysis, weighting method, entropy evaluation method, standard value method, etc. However, the complexity to obtain research data is quite different for the difference in research region, so evaluation indices and calculation methods used in study are different from each other. Currently, there is no evaluation model for urbanization development quality recognized by the academy. This study selected 18 second-level indicators in five aspects of economy, environment, society, life and population to construct the comprehensive evaluation system for urbanization development quality of Xiangyang City. With this system, we calculated comprehensive quality indices of urbanization development quality of Xiangyang City since 2000. Meanwhile, economic structural index, environmental development index, social development index, life quality index and population quality index were constructed for analysis of urbanization development quality of Xiangyang City. This analysis will give scientific evidence and decision support to coordinate and promote healthy urbanization development of Xiangyang City.

2.1 Evaluation index system and weights of urbanization development quality

With the availability, scientificity and hierarchy of urbanization data for Xiangyang City, Table 1 shows 5 first level indicators of criterion layer, including economic development quality index, social development quality index, environmental development quality index, life quality index and population development quality index, as well as 18 secondary level indicators in criterion layer determined according to the general goal of urbanization development quality score. All the index weights can be determined with analytic hierarchy process supported by entropy technology (Li Zhiming, 2007) and approved by 0.01 consistency check.

Table 1 shows the weights of indicators in every level against the upper goal to determine the influence degree of indicator to the general goal. The calculation of evaluation index weight shows that the economic index plays an extremely important role in urbanization development quality, while the GDP per capita is the most important. The quality of regional urbanization development is closely related to regional economic development level. Moreover, the living quality of residents also determines the urbanization development degree to great extent, so the living quality should be improved to increase the urban comprehensive strength in present stage. 
Table 1 Evaluation index system, weight and discrimination standard value for urbanization quality of Xiangyang City

\begin{tabular}{|c|c|c|c|c|c|}
\hline $\begin{array}{l}\text { The first } \\
\text { level index }\end{array}$ & The second level index & Unit & \multicolumn{2}{|c|}{ Weight } & $\begin{array}{l}\text { Discrimi } \\
\text { nation } \\
\text { standard } \\
\text { value }\end{array}$ \\
\hline \multirow{4}{*}{$\begin{array}{l}\text { Economic } \\
\text { developme } \\
\text { nt quality }\end{array}$} & GDP per capita & Hundred million & 0.1050 & \multirow{4}{*}{0.279} & $\geq 45000$ \\
\hline & Ratio of tertiary industry & $\%$ & 0.0751 & & $\geq 50$ \\
\hline & $\begin{array}{l}\text { Ratio of added value of high and new technology } \\
\text { industry occupying in added value of industry }\end{array}$ & $\%$ & 0.0804 & & $\geq 25$ \\
\hline & Ten thousand Yuan GDP energy consumption & $\begin{array}{c}\text { Tons standard } \\
\text { coal/ten thousand } \\
\text { Yuan } \\
\end{array}$ & 0.0185 & & $\leq 0.6$ \\
\hline \multirow{4}{*}{$\begin{array}{l}\text { Environme } \\
\text { ntal } \\
\text { developme } \\
\text { nt quality }\end{array}$} & Green coverage ratio in built-up area & $\%$ & 0.0536 & \multirow{4}{*}{0.134} & $\geq 40$ \\
\hline & Treatment rate of waste water & $\%$ & 0.0134 & & 100 \\
\hline & Harmless treatment rate of rubbish & $\%$ & 0.0128 & & 100 \\
\hline & $\begin{array}{l}\text { Comprehensive utilization rate of industrial solid } \\
\text { wastes }\end{array}$ & $\%$ & 0.0503 & & $\geq 80$ \\
\hline \multirow{4}{*}{$\begin{array}{c}\text { Social } \\
\text { developme } \\
\text { nt quality }\end{array}$} & Water popularizing rate & $\%$ & 0.0372 & \multirow{4}{*}{0.223} & $\geq 100$ \\
\hline & Road surface per capita & Square meter & 0.0208 & & $\geq 15$ \\
\hline & Doctor number per thousand people & Person & 0.0662 & & $\geq 4.8$ \\
\hline & $\begin{array}{l}\text { Teacher number for basic education per hundred } \\
\text { people }\end{array}$ & Person & 0.0662 & & $\geq 2.5$ \\
\hline \multirow{3}{*}{$\begin{array}{l}\text { Life } \\
\text { quality }\end{array}$} & Urban per capita disposable income & Yuan & 0.132 & \multirow{3}{*}{0.252} & $<0.2$ \\
\hline & Living spaceper capita & Square meter & 0.0954 & & 30000 \\
\hline & Urban green area & Hectare & 0.0246 & & 40 \\
\hline \multirow{3}{*}{$\begin{array}{l}\text { Population } \\
\text { quality }\end{array}$} & Ration of urban population & $\%$ & 0.0613 & \multirow{3}{*}{0.112} & $\geq 15$ \\
\hline & Children enrollment rate & $\%$ & 0.0203 & & $\geq 80$ \\
\hline & Unemployment rate & $\%$ & 0.0304 & & 100 \\
\hline
\end{tabular}

Note: The judgment standard should be determined with relevant research results of scholars and authority departments

\subsection{Data sources and standardization}

The study period selected in this work is 2000-2012, and all the index data are from Hubei statistical yearbook, Xiangyang statistical yearbook, city yearbook of China, city construction yearbook of China, health yearbook of China and environmental statistics yearbook of China. All the indices obtained from original data are different from each other in aspects, including content, dimension and value advantages and disadvantages, so it is necessary to turn all the indices into relatively unified dimension. The data standardization aims at eliminating all the difference of variable value in magnitude order to improve the comparability between data. The mathematical formula adopted for standardization of original data with matlab software is as follows:

$$
Z=\left(x_{i}-\bar{x}\right) / S D
$$

where $Z$ is the standardized value of original data, original observed value, average data and standard deviation. The average value of new variables after standardization is 0 and the standard deviation is 1 . Variable value less than 0 shows the value is lower than average level and vice versa. In order to be subject to the observation habit, we will modify the standard value to make modification value of every index non-negative. The mathematical formula adopted in modification is as follows:

$$
P=\left[\left(Z-x_{\min }\right) /\left(x_{\max }-x_{\min }\right)\right] \times 100 \quad \text { (2) }
$$

where $P$ is modification value;Zstandardized value; $x_{\min }$ the minimum after standardization; and $x_{\max }$ the maximum after standardization. Therefore, the modification value is between 0 and 100 .
2.3 Calculation for urbanization development quality of Xiangyang City and the comparison with population urbanization

The study on urbanization development quality index uses $S_{i j}$ to represent the score of the jth secondary-level index for the ith evaluation factor, where $i$ is the order of first-level index $(i=1,2,3, \ldots . .5)$, and $j$ the order of second-level index. Therefore, $S_{i j}=W_{i j} * X_{i j}$ ( $W_{i j}$ is the weight of each index, and $X_{i j}$ is the modification value) can be got. The summation will be made for the second-level index with $S_{i}=\sum_{j} S_{i j}$, where $S_{i}$ is the score of the $i$ th first-level evaluation index. The score for urbanization development quality can be obtained with $T g=\sum_{i=1}^{5} S_{i}(g=1,2, \ldots \ldots 19)$ (see in Table 2). 
Table 2 Modification value and comprehensive index of the first-level indicators for urbanization quality in Xiangyang City for many years

\begin{tabular}{c|c|c|c|c|c|c}
\hline & $\begin{array}{c}\text { Economic } \\
\text { development } \\
\text { quality }\end{array}$ & $\begin{array}{c}\text { Environmental } \\
\text { development } \\
\text { quality }\end{array}$ & $\begin{array}{c}\text { Social } \\
\text { development } \\
\text { quality }\end{array}$ & $\begin{array}{c}\text { Life } \\
\text { quality }\end{array}$ & $\begin{array}{c}\text { Population } \\
\text { quality }\end{array}$ & $\begin{array}{c}\text { Urbanization } \\
\text { quality index }\end{array}$ \\
\hline 2000 & 8.00 & 0.5148 & 15.055 & 1.212 & 2.48 & 30.42 \\
\hline 2001 & 9.45 & 1.873 & 16.65 & 1.641 & 1.84 & 30.07 \\
\hline 2002 & 10.71 & 2.611 & 15.50 & 0.186 & 0.499 & 33.02 \\
\hline 2003 & 11.17 & 4.41 & 18.34 & 1.202 & 4.88 & 48.08 \\
\hline 2004 & 11.93 & 4.436 & 17.43 & 4.231 & 5.48 & 44.06 \\
\hline 2005 & 12.33 & 4.73 & 17.22 & 2.622 & 6.47 & 42.18 \\
\hline 2006 & 14.57 & 4.90 & 18.07 & 2.799 & 6.62 & 42.89 \\
\hline 2007 & 14.29 & 6.439 & 17.29 & 3.653 & 7.33 & 68.30 \\
\hline 2008 & 7.49 & 7.651 & 9.369 & 7.551 & 7.95 & 53.09 \\
\hline 2009 & 16.04 & 7.578 & 13.58 & 5.877 & 8.68 & 56.00 \\
\hline 2010 & 19.87 & 6.997 & 14.18 & 4.345 & 9.18 & 47.622 \\
\hline 2011 & 24.14 & 6.731 & 13.10 & 4.613 & 9.85 & 43.88 \\
\hline 2012 & 27.90 & 7.655 & 12.42 & 6.267 & 10.39 & 43.33 \\
\hline
\end{tabular}

This work took advantage of United Nations laws (Zhou Yixing, 2003) to calculate the urbanization development level of Xiangyang City according to the urban population ratio published in the $5^{\text {th }}$ and $6^{\text {th }}$ nationwide census. The urbanization rate of Xiangyang City in 2000 2012 is modified as follows:

$$
U R G D=\ln \left(\frac{P U(2) /[1-P U(2)]}{P U(1) /[1-P U(1)]}\right) / n
$$

where $U R G D$ is the growth rate of population; $P U(1)$ the urban population proportion in the previous census; $P U(2)$ the urban population proportion in the next census; and $n$ the year between two censuses. Table 3 shows the calculation results.

Table 3 Modified urbanization level of Xiangyang City

\begin{tabular}{c|c|c|c|c|c|c|c|c|c|c|c|c}
\hline 2000 & 2001 & 2002 & 2003 & 2004 & 2005 & 2006 & 2007 & 2008 & 2009 & 2010 & 2011 & 2012 \\
\hline 26.7 & 29.8 & 31.9 & 34.2 & 36.5 & 38.9 & 41.4 & 44 & 46.7 & 49.3 & 50.3 & 51.2 & 53 \\
\hline
\end{tabular}

According to the table for calculation analysis on urbanization quality calculation of Xiangyang City, the urbanization development quality of Xiangyang City shows no steady growth like urbanization level. During 2000-2012, the growth fluctuation of urbanization development quality of Xiangyang City is larger. The period can be divided into two major stages, growth period with fluctuation from 2000-2007 and period with decreased growth but better development quality from 2007-2012. Urbanization quality index in 2007 is the highest, and then it decreases year by year, which is caused by the decrease of economic and social development quality. Although GDP of Xiangyang City increases rapidly for years, the proportion of tertiary industry in GDP does not increase but decreases, while the output value of high and new technology industry increases sharply with decreased proportion in total industrial output value. According to the synthesis score of urbanization quality index and the standard for level division of urbanization development quality (see in Table 4) put forward by Kong Fanwen (2006), the urbanization development quality of Xiangyang City has been greatly improved, but the overall quality is still low. Therefore, urbanization quality should be promoted greatly in the future.

Table 4 Standard for level division of urbanization development quality

\begin{tabular}{c|c}
\hline $\begin{array}{c}\text { Comprehensive index of } \\
\text { urbanization quality }\end{array}$ & Urbanization quality \\
\hline$\geq 90$ & High \\
\hline $80 \sim 90$ & Relatively high \\
\hline $70 \sim 80$ & General \\
\hline $60 \sim 70$ & Relatively low \\
\hline
\end{tabular}

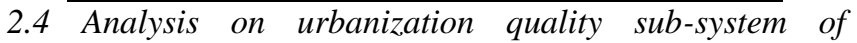
Xiangyang City

In order to find the key factors affecting urbanization development quality of Xiangyang City, economic structural index, environmental protection index, social security index, life quality index and population quality index will be adopted in study on development situation of urbanization quality sub-systems of Xiangyang City.

Economic structure includes analysis indices representing the massive structure of industrial economy and the structural update of industrial industry. Its calculation formula is as follows:

$$
E S I=\frac{2}{3}\left(\frac{t_{i}}{S_{1}}\right)+\frac{1}{3}\left(\frac{p_{i}}{S_{2}}\right)
$$

where $t_{i}$ is the ratio of tertiary industry in GDP; $p_{i}$ the ratio of added value for high and new technology industry in industrial added value; and $s_{l}$ and $s_{2}$ are corresponding standard values.

Social development quality, which is reflected by social security index, can be expressed as follows:

$$
I D I=\frac{2}{3}\left\{\frac{1}{3}\left[\left(\frac{w_{i}}{s_{1}}\right)+\left(\frac{h_{i}}{s_{2}}\right)+\left(\frac{r_{i}}{s_{3}}\right)\right]\right\}+\frac{1}{3}\left(\frac{d_{i}}{s_{4}}\right)
$$

where $w_{i}$ is the water popularizing rate; $h_{i}$ the road area per capita; $r_{i}$ the doctor number per thousand people; $d_{i}$ the 
teacher number for basic education per hundred people; and $s_{1}, s_{2}, s_{3}$ and $s_{4}$ are corresponding standard values.

Environmental development quality can be calculated with following calculation formula by environmental index:

$$
E E S I=\frac{2}{3}\left\{\frac{1}{3}\left[\left(\frac{a_{i}}{s_{1}}\right)+\left(\frac{b_{i}}{s_{2}}\right)+\left(\frac{c_{i}}{s_{3}}\right)\right]\right\}+\frac{1}{3}\left(\frac{g_{i}}{S_{4}}\right)
$$

(6)

where $a_{i}$ is the treatment rate of waste water; $b_{i}$ the harmless treatment rate of rubbish; $c_{i}$ the comprehensive utilization rate of industrial solid waste; $g_{i}$ the green coverage ratio in established area; and $s_{1}, s_{2}, s_{3}$ and $s_{4}$ are corresponding standard values.

Calculation formula of life quality index is as follows:

$$
H S I=\frac{2}{3}\left(\frac{f_{i}}{S_{1}}+\frac{k_{i}}{S_{2}}\right)+\frac{1}{3}\left(\frac{e_{i}}{S_{3}}\right)
$$

where $f_{i}$ is urban per capita disposable income; $k_{i}$ the living area per capita; $e_{i}$ the urban green area; and $s_{1}, s_{2}$ and $s_{3}$ are corresponding standard values.

The calculation formula of population quality index is as follows:

$$
P S I=\frac{2}{3}\left(\frac{l_{i}}{S_{1}}+\frac{m_{i}}{S_{2}}\right)+\frac{1}{3}\left(\frac{n_{i}}{S_{3}}\right)
$$

where $l_{i}$ is the ratio of urban population; $m_{i}$ the children enrollment rate; $n_{i}$ the unemployment rate; and $s_{1}, s_{2}$ and $s_{3}$ are corresponding standard values.

Table 1 shows the discrimination standard values of each index for above urbanization development quality sub-system.

According to the criteria of urbanization quality development and calculation results of index formula for sub-system, index values of sub-systems are calculated (see in Table 5), and evolution process map is drawn (see in Fig. 1)for urbanization quality of Xiangyang City from 2000 to 2012.

Table 5 2000-2012 decomposition analysis for urbanization development quality in classification of Xiangyang City

\begin{tabular}{c|c|c|c|c|c}
\hline Year & $\begin{array}{c}\text { Economic structural } \\
\text { index }\end{array}$ & $\begin{array}{c}\text { Social development } \\
\text { index }\end{array}$ & $\begin{array}{c}\text { Environment } \\
\text { al index }\end{array}$ & $\begin{array}{c}\text { Life qualityindex } \\
\text { Population quality } \\
\text { index }\end{array}$ \\
\hline 2000 & 0.751 & 0.416 & 0.658 & 0.662 & 1.192 \\
\hline 2001 & 0.754 & 0.430 & 0.735 & 0.674 & 1.168 \\
\hline 2002 & 0.890 & 0.424 & 0.743 & 0.692 & 1.168 \\
\hline 2004 & 0.920 & 0.442 & 0.848 & 0.735 & 1.306 \\
\hline 2005 & 0.791 & 0.445 & 0.883 & 0.785 & 1.315 \\
\hline 2006 & 0.829 & 0.443 & 0.854 & 0.840 & 1.343 \\
\hline 2007 & 0.829 & 0.445 & 0.874 & 0.885 & 1.345 \\
\hline 2008 & 1.298 & 0.439 & 0.963 & 0.916 & 1.371 \\
\hline 2009 & 1.391 & 0.395 & 1.098 & 0.932 & 1.416 \\
\hline 2010 & 1.033 & 0.422 & 1.105 & 1.029 & 1.449 \\
\hline 2011 & 0.909 & 0.431 & 1.051 & 0.983 & 1.469 \\
\hline 2012 & 0.877 & 0.424 & 1.037 & 1.104 & 1.478 \\
\hline
\end{tabular}

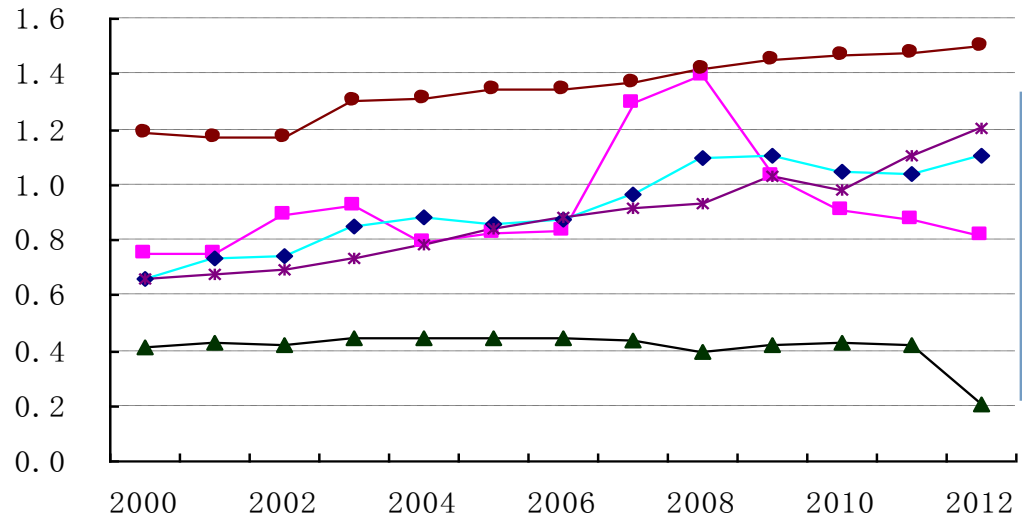

Economic structural index Social development index Environmental index Life quality index Population quality index

Fig. 1 2000-2012 evolution process for urbanization quality sub-system of Xiangyang City 
According to the changes of specific indices, the economic structural index of Xiangyang City increased from 0.754 to 1.391 in 2000-2008, and gradually decreased to 0.815 later. It is mainly because in recent years, the ratio of output value for tertiary industry in Xiangyang City in GDP, and added value of high and new technology industry in industrial added value decreased. Moreover, the GDP consumption per ten thousand Yuan in Xiangyang (1.03 tons standard coal/ten thousand Yuan in 2012) is higher, which is also an important "bottleneck" factor for low economic development quality. Compared with the urbanization comprehensive development quality level, the cost of economic development is so large that the speed of economic structural update lags.

The social development index changes a little, but it decreases in recent years. It is mainly because the doctor number in Xiangyang has not increased for many years, and the teacher number for basic education decreases, while the total population increases.

Environmental protection index is relatively high and tends to increase. It increases from 0.658 in 2000 to 1.103 in 2012, which represents that the urbanization development of Xiangyang City has a better environmental basis. The good rate of air in Xiangyang City is up to $80 \%$ for many years, and the green coverage ratio in established area is more than $40 \%$. Treatment rate of sewage, harmless treatment rate of domestic garbage and recycling ratio of solid wastes, increasing year by year, has been up or close to $100 \%$.

Living quality index quickly increases from 0.662 in 2000 to 1.207 in 2012 . It is mainly because the urban per capita disposable income and living area per capita increase quickly.

Population quality index increases in small rate, because the unemployment rate in Xiangyang City is low, and the children enrollment rate is high, while the urban population ratio increases year by year.

\section{MEASUREMENT FOR URBANIZATION DEVELOPMENT QUALITY PROMOTION IN XIANGYANG CITY}

Based on above-mentioned research results, urbanization development quality can be improved in following aspects for Xiangyang City:

3.1 Paying attention to coordination between urbanization speed and quality

Scientific analysis is conducted for urbanization development level of Xiangyang City combining the field situation on basis of comprehensive consideration of urbanization development quality and level. Moreover, the appropriate population urbanization level will be rationally estimated based on regional urbanization development quality. During urbanization, the development rules should be followed without aimless pursuit of high urbanization rate to avoid drastic fluctuations. In addition, the development speed should be matched with economic development quality, social development quality and resource and environmental security quality, to correctly handle mutual relation among urbanization development level, speed and quality.

3.2 Accelerating technical update and reducing energy consumption

Economic structural index of Xiangyang City with large urban-rural gap tends to reduce after increasing. Environmental security index is relatively high, but the resource and energy consumption for economic social development is also high. The GDP energy consumption per ten thousand in 2012 was 0.97 ton standard coal. The relatively high cost of economic development is an important "bottleneck" factor causing low economic development quality. In addition, water transfer in Middle Route Project of S-N Water Diversion greatly reduces the water resource, so the environmental situation is not optimistic. In the future, more attention should be paid to economic efficiency improvement based on the stabilization of urbanization development level to promote the transformation of industrial structure. In order to reduce the cost for economic development, water-saving and energy-saving industries are developed, and technical transformation of industry with high water and energy consumption is accelerated to reduce the proportion of industries with high energy and water consumption.

3.3 Optimizing transformation and improving high and new technology industry development level

In order to improve the urbanization development quality of Xiangyang City, no effort should be spared in driving the development of advanced manufacturing industry and modern service industry. By optimizing the three times industrial structure and the internal structure of industry, the economic growth mode is transformed constantly for the positive encouragement of innovation with the increasing ratio of added value for tertiary industry in gross national product. High and new technology industry becomes the strong power driving sustainable growth of economy to build Xiangyang City as a characteristic advanced manufacturing base and modern service industry cluster, driving economy in Xiangyang develop healthily and sustainably.

3.4 Taking multiple measures and promoting synchronous development of city and country

At first, mechanism matched, with fair urban-rural public finance and equal urban-rural public service, is established for enhancing the support from public finance to rural public project, realizing the equal support to both rural and urban public infrastructures.

Secondly, the mechanism for butt joint between agricultural production circulation method and urban agricultural product consumption update is developed to improve the organization degree for agricultural production circulation. The agricultural product production logistic system, effectively connecting modern agricultural production and management subject with modern agricultural product circulation subject, is constructed with 
efforts. In addition, supply mechanism providing high-quality and safe agricultural products to the city is also built.

Thirdly, leisure agriculture and innovative agriculture are greatly developed to promote agricultural production value chain. Therefore, an effective mechanism for mutual promotion between urban and rural industries will be formed.

\section{ACKNOWLEDGEMENT}

This work is one of the achievements of Program for Excellent Young and Middle-aged Technological Innovation Plan of Hubei Provincial Universities and Colleges (T201314) and Special Program for Xiangyang Technology Plan and Soft Science (Study on Urbanization Development Quality Evaluation and Promotion Strategy of Xiangyang City).

\section{REFERENCES}

[1] Ye Yumin, "Approach on China's Urbanization Quality", China Soft Science. 2001 (7): 27-31.

[2] Bai Xianchun, Ling Kang, Guo Cunzhi, et al., "China's Urbanization: Level Estimation and International Comparison", Urban Problems. 2004(2): 23-26.

[3] Wang Deli, Fang Chuanglin, Yang Qingshan, et al., "Judgment Analysis on Chinese Urbanization Development Speed Based on Urbanization Quality", Chinese Geographical Science. 2010, 30(5): 643-650.

[4] Xu Su, Yu Tao, Wu Qiang, "A Study of Urbanization Quality Assessment System of County-level Cities in China Under the Regional Perspective: Taking the Yangtze Delta Area as An Example", Urban Planning International. 2011 (01): 53-58.

[5] Ou Minghao, Li Wuyan, et al., "Study on Compression Level and Ideal Impetus of Regional Urbanization: A Case Study of Jiangsu Province", Resource and Environment in Yangtze River Basin. 2004, 13, (5): 408-412.

[6] Yu Tao, Zhang Jingxiang, Luo Xiaolong, "Research on Urbanization Quality of County-Level Cities in Eastern Developed Area of China_-A Case Study of Changshu City”, Urban Studies. 2010 (11): 7-12.

[7] He Jian, et al., "A Measure Study on the Urbanization Quality of Shandong Province", Chinese Famous City (urbanization and strategic positioning) 2013, 6: 25-29.

[8] Li Zhiming, "Research on Urbanization Quality in Jiangjin District of Chongqing", Master's thesis of Southwest University 2007, 4.

[9] Zhou Yixing, "Urban Geography", Beijing: The Commercial Press, 2003.

[10] Wang Deli, "Study on Regulation Mechanism and Promotion Strategies of China Urbanization Development Quality", Doctoral thesis from Institute of Geographic Sciences and Natural Resources Research, CAS, 2011, 5.

[11] Kong Fanwen, Xu Shiwei, "Research on the Speed and Quality of Chinese Urbanization", Northeastern University Press. 2006. 